\title{
O ETHOS DA CULTURA DA EDUCAÇÃO BRASILEIRA
}

\author{
THE ETHOS OF CULTURE IN THE BRAZILIAN EDUCATION
}

Daniel Chris Amato ${ }^{1}$

AMATO, D. C. O Ethos da cultura da educação brasileira. Akrópolis Umuarama, v. 27, n. 2, p. 111-118, jul./dez. 2019.

DOI: 10.25110/akropolis.v27i2.7572

${ }^{1}$ Mestre em Desenvolvimento Humano e Tecnologias na UNESP, Campus de Rio Claro (2016-2017), sob a orientação do Prof. Dr. Adriano Polican Ciena e Coorientação da Profa. Silvia Deutsch. Especialista em Educação Musical pelo UNASP-EC (2012). Graduado em Educação Artística com licenciatura em música pelo UNASP (2011). Bacharel em Administração de Empresas pela ASSER (1997). É Professor (PEBIII-Arte) da Rede Municipal de Ensino de Campinas, onde desenvolve atividades no Projeto Cantando na Escola. Atuou como docente da UNINCOR, em Três Corações-MG, no curso de Licenciatura em Música na modalidade EaD; na Faculdade de Campo Limpo Paulista (FACCAMP) no curso presencial de música e na pós graduação de Educação Musical e também no MBA Engenharia Logística. Também atua como docente na Pós Graduação Lato Sensu (presencial) no Centro Sul-brasileiro de Pesquisa, Extensão e Pós-graduação (CENSUPEG). É tutor virtual do curso de música da Universidade Federal de São Carlos (UFSCar). Nesta mesma universidade atuou como professor substituto no curso de licenciatura em música (presencial). Atua como regente do Madrigal Nós por Voz e é elaborador do Projeto Sinfonia Coral que reúne corais de diversas cidades para execução de obras sinfônicas. Tem experiência na área de Artes, com ênfase em Música, atuando principalmente nos seguintes temas: políticas públicas em educação musical, coral adulto, coral de $3^{\text {a }}$ idade, coral infantil, técnica vocal, cultura popular e capoeira, tecnologias e desenvolvimento humano e musicalização. maestrodanielamato@gmail.com
Resumo: Este trabalho discute o papel da Educação a partir afirmação explicitada nos PCN de 1998 diante da visão de Mário Vieira de Mello (1912 - 2006). Na busca pela qualidade de ensino os currículos são adequados às realidades urbanas a partir de modelos importados, muitas vezes sem uma análise profunda do papel que a sociedade deseja que a Educação desempenhe. A reflexão sobre os conceitos de liberdade e igualdade para a democracia podem levar os educadores a outros posicionamentos, considerando autores que buscam na Educação a transcendência do Ethos, não da maneira possível, mas enfrentando as idiossincrasias e paradoxos que apresenta nossa democracia. Diante dessa proposição, o artigo responda e seguinte pergunta: - A Educação Brasileira pode dar suporte necessário para uma democracia com plena liberdade aos seus cidadãos? Como resposta, sugere-se a implantação de uma nova Educação cujo o grande desafio é torná-la suficiente para atender a demanda por profissionais capacitados e devidamente educados para exercer sua liberdade plena na democracia cultivando a liberdade interna a partir do conceito de Ethos.

PAlavras-chave: Educação; Ética; Qualidade na Educação.

ABSTRACT: This paper discusses the role of Education from an explicit statement in the 1998 PCN [National Syllabus Program] before the vision of Mario Vieira de Mello (1912 - 2006). In the quest for quality education, curricula are adapted to urban realities from imported models, often without an in-depth analysis of the role that society wants education to play. The reflection on the concepts of freedom and equality for democracy can lead educators to other opinions, considering authors who seek in education the transcendence of Ethos, not in the possible way, but by facing the idiosyncrasies and paradoxes that our democracy presents. Faced with this proposition, the article answers the following question: Can the Brazilian Education provide the necessary support for a democracy with full freedom for its citizens? In response, it suggests the implementation of a new Education with the great challenge of making it sufficient to meet the demand for trained and properly educated professionals to exercise their full freedom in the democracy by cultivating internal freedom from the Ethos concept. KeYWORDS: Education; Ethics; Quality in Education. 


\section{INTRODUÇÃO}

Este trabalho propõe uma discussão sobre o papel da Educação a partir afirmação explicitada nos PCN de 1998, diante da visão de Mário Vieira de Mello (1912 a 2006).

$\mathrm{Na}$ busca pela qualidade de ensino os currículos são adequados às realidades urbanas a partir de modelos importados, muitas vezes sem uma análise profunda do papel que a sociedade deseja que a Educação desempenhe. A reflexão sobre os conceitos de liberdade e igualdade para a democracia pode levar os educadores a outros posicionamentos, considerando autores que buscam na Educação a transcendência do Ethos, não da maneira possível, mas enfrentando as idiossincrasias e paradoxos que apresentam nossa democracia. Para a implantação de uma nova educação, o grande desafio é torná-la suficiente para atender a demanda por profissionais capacitados e devidamente educados para exercer sua liberdade plena na democracia.

Esse artigo foi construído a partir de pesquisa bibliográfica com foco em Mello (1986), não dispensando outras referências como Vitorino (2011), Nietzshe (2008), Platão (1979), de maneira promover uma análise das discussões sobre a busca da qualidade na Educação brasileira e na manutenção da democracia, em resposta da seguinte pergunta:

- A Educação Brasileira pode dar suporte necessário para uma democracia com plena liberdade aos seus cidadãos?

Deve-se considerar como liberdade a possibilidade de escolha do acolhimento de um espírito ético, como preconiza Mello (1986), o autor em foco nesse trabalho.

\section{DA LEI À REALIDADE}

A conceituação moderna para a educação, no que tange à sua qualidade, é uma preocupação constante e atual dos gestores e acadêmicos de nosso tempo. Partindo do pressuposto descrito nos Parâmetros Curriculares Nacionais em 1998, temos no prefácio escrito pelo então Ministro da Educação e do Desporto, Paulo Renato Souza, que

O papel fundamental da educação no desenvolvimento das pessoas e das sociedades amplia-se ainda mais no despertar do novo milênio e aponta para a necessidade de se construir uma escola voltada para a formação de cidadãos. Vivemos numa era marcada pela competição e pela excelência, onde progressos científicos e avanços tecnológicos definem exigências novas para os jovens que ingressarão no mundo do trabalho. Tal demanda impõe uma revisão dos currículos, que orientam o trabalho cotidianamente realizado pelos professores e especialistas em educação do nosso país (BRASIL, 1998, p.5).

A construção de uma nova escola, nesse trecho, não se refere a apenas constituir a formação de cidadãos, mas também de propor que os jovens sejam competitivos, considerando a constituição dos currículos vigentes e daqueles a serem implementados, visando maior performance nos instrumentos de avaliação de qualidade. Os resultados esperados nas avaliações aplicadas pelos órgãos oficiais, como o SARESP $^{2}$ explicitaram uma tendência na intenção do Governo Alckmin noticiada pelo portal da APEOESP ${ }^{3}$, em 2013. Em Mello (1986), pode-se constatar que

O homem da rua pode hoje ler qualquer jornal aquilo que Nietzsche denunciou faz quase um século. $O$ mundo inteiro está em crise. Há crise religiosa, crise social, crise política, crise econômica e há, naturalmente, a maior delas, a crise espiritual que é, entretanto, a de que menos se fala (MELLO, 1986, p.14).

Esse autor considera Nietzsche como um "educador, isto é, um homem cujo gênio consistia em descobrir os vícios, males e distorções intelectuais e morais de que está sofrendo a humanidade" (MELLO, 1986, p.14).

Como ponto de partida, discute-se que o educador tem por vocação "atacar a realidade para transformá-la, para regenerá-la, para conduzi-la"(MELLO, 1986, p.15). A transformação da realidade só é necessária quando se há uma crítica latente à espera por um avanço, por um passo adiante, contudo ela pode ser necessária devido à existência de uma crise, ao descompasso em atender aos anseios da sociedade. Vitorino (2011), aproxima os conceitos de crise,

\footnotetext{
2Sistema de Avaliação do Rendimento Escolar do Estado de São Paulo

${ }^{3}$ Sindicato dos Professores do Ensino Oficial do Estado de São Paulo
} 
afirmando que:

Crise, no entanto, enquanto léxico, é uma velha palavra. Este termo vem do grego "Krisis", e significava separação, divisão, abismo, e, também, juízo, decisão. "Krisis" também é derivada do verbo "Krinein". Deste modo, crise e crítica são irmãs siamesas. Isto se torna evidente quando a crítica vem sob a forma de ambigüidade e duplicidade, apresentando dificuldades em vislumbrar o devir, apesar de não aceitar o mundo, as coisas e os valores presentes (VITORINO, 2011, p.01).

Diante disso, pode-se considerar que a Educação atual ainda apresenta uma crise na busca da qualidade que atenda ao mercado e a própria existência do saber. Para o mais incauto seria fácil identificar que certos objetivos da Educação Fundamental previstos em lei não apresentam consistência para serem cumpridos na prática. No texto dos $\mathrm{PCN}$, pretende-se que o aluno seja capaz de

[...] questionar a realidade formulando-se problemas e tratando de resolvê-los, utilizando para isso o pensamento lógico, a criatividade, a intuição, a capacidade de análise crítica, selecionando procedimentos e verificando sua adequação (BRASIL, 1998, p.8).

\section{Sobre isso, Mello (1986), afirma que}

A posição dialética é o sinal infalível de que uma época está em crise. $E$ as crises existem quando o que é apenas possível pretende se substituir ao que é verdadeiramente real. Mas podemos também dizer que as crises surgem justamente quando se exaurem as fontes de credibilidade onde vão se alimentar as verdades expostas por um método direto; quando a verdade que nos é comunicada de modo direto não mais nos convence (MELLO, 1986, p. 271)

Por sua vez, Vitorino (2011, p.01) concorda afirmando que uma crise está instalada "quando enfrentamos uma situação cuja retórica procura inverter dialeticamente os sinais para provar o que bem se entende e se quer, mas não a verdade do mundo e das coisas que nos cercam", daí a necessidade emergencial da bus- ca por um método mágico que resulte na solução da crise pela qualidade. Então, diante dessa crise moral, a que se refere Nietzsche (1998), pode-se inferir que a crise na educação, cujo papel do educador sofre distorções, pode conceber um educador pessimista ou otimista. Pessimista pelo fato das estruturas socioeconômicas estarem desfavoráveis, ou pelas inadequações dos métodos, ou pela falta de recursos ou por toda sorte de obstáculos a serem transpostos para uma eficiente educação nos moldes socráticos. Otimista por definição, pois o educador tem por convicção que tais obstáculos podem ser transpostos para se tornar um verdadeiro educador, como pregam muitas campanhas de incentivo e premiação oficial aos professores que se destacam pela eficiência de ensino e motivação junto aos alunos ${ }^{4}$. Nesse contexto, Mello (1986) desconsidera o ser professor como o ideal a ser premiado. Em que pese os pilares da educação contemporânea ${ }^{5}$, o fato é que a educação, como preconiza Sócrates, não pode atuar diante das gestões para a educação das massas no moldes modernos.

Independentemente da discussão do mérito dos prêmios, alcançar a excelência tornou-se prioritário como já citado. Nietzsche (2009) já apontava que a igualdade não passa de um engodo ou um embuste, pois os homens não são iguais e, portanto, não deveriam ser tratados como iguais. Então, uma proposta é promover a excelência na Educação por meio de uma Educação voltada para a liberdade, distante da Educação igualitária, em que todos podem alcançar os mesmos objetivos por serem iguais. Para essa procura não se deve considerar a educação casual ou formal, aquela encontrada nos guetos sociais ou escolas tradicionais, pois trata-se da Educação que parte a cultura, ancorada nos valores e ideias do indivíduo, remetendo-o à coletividade, formando uma elite que emergirá das massas. Não se deve entender elite como privilégio, mas como escolha do indivíduo, podendo emergir com liberdade das massas no momento que se deixar tocar pela

${ }^{4}$ Estes prêmios são, geralmente, instituídos para que os professores sejam eleitos pela comunidade como força de reconhecimento coletivo de sua trajetória profissional. Como bons exemplos pode-se citar o Prêmio Professores do Brasil que é uma iniciativa do Ministério da Educação, promovido juntamente com as instituições parceiras, assim como o conquistado pelo brasileiro Alexandre Lopes, concedido pelo Departamento de Educação do governo norte-americano e recebido pelas mãos de seu presidente, Barack Obama.

${ }^{5}$ Democracia, tecnologia e ciência. 
Educação para a liberdade.

No entanto, deve-se considerar que a democracia esteja a serviço da educação e não o contrário, pois essa é a responsável por preservar o conceito de ideias em toda sua integridade. Não é de estranhar que Rousseau (apud MELLO, 1986) tenha se referido a Platão (1979) e sua obra República:

Mas ele (Rousseau) toma a posição contrária. Depois de reconhecer que a educação pública em si seria uma coisa muito desejável ele a afasta abruptamente como possibilidade sob o pretexto de que é incompatível com as condições da sociedade contemporânea (MELLO, 1986, p. 237). [sic autor]

Apesar das afirmações serem compatíveis, a princípio, no contexto histórico da Europa do séc. XVIII, elas podem servir como um intrigante ensaio para a Educação atual. A obra de Platão, ao contrário do que pensam muitos filósofos modernos e contemporâneos, principalmente anglo-saxões, sua obra A República é um ensaio sobre política num Estado totalitário. Por essa razão, o seu ideal de Ethos certamente não está por ser alcançado pela democracia que se instalou nos países que são modelos para o Brasil, como os EUA, independentemente do modelo político adotado.

Para a discussão sobre a Educação, no entanto, se faz necessário

\section{[...] fixarmos de modo mais preciso o que temos em mente, vamos em primeiro lu- gar indicar em linhas gerais como uma sociedade com aspirações à liberdade, mas não representativa do monopólio de um determinado tipo de liberdade, poderia se exercer o escrutínio do pes- quisador, o olhar livre do filósofo a partir da distinção essencial entre dois tipos de liberdade: uma dada plena democra- cia e outra pela educação (MELLO,1986 p.86).}

A democracia moderna de Mello (1986), é reflexo da busca pela igualdade pelos cidadãos, fruto de uma constante luta nacionalista que foi pontuada em alguns episódios, como a revelação ao Povo de Israel do Deus único no firmamento de uma aliança eterna; no surgimento da Pólis de Atenas, inspirando a democracia grega; e a Revolução Americana como marco da modernidade com a construção sob o marco da igualdade. Revolução esta que enfatizou a própria contradição com seu lema: Liberdade, Igualdade e Fraternidade. Embora pareçam uma trindade uníssona, Mello (1986) reforça sua divergência quando distingue a Liberdade da Igualdade, pois cada um está em uma estrutura própria que aponta para condutas sociais estruturais muito distintas.

Os campeões da igualdade tornaram-se inimigos da liberdade e os campeões da liberdade tornaram-se senão inimigos da igualdade pelo menos os inimigos da igualdade conquistada com o sacrifício da liberdade (MELLO, 1986, p.87).

Nos EUA, como modelo pragmático para nossa Educação, realizaram uma revolução que provocou a ruptura com o modelo da tradição cultural europeia, apoiando-se numa estrutura de poder, acreditando ser possível que a liberdade seja alcançada no caminho da promoção da igualdade dos indivíduos, esquecendo-se do Ethos de Sócrates e Platão. A preocupação para com os procedimentos formais e institucionais, implementando acesso aos direitos individuais impostos pelo Estado ou governo, aproximam da tirania refletida da visão platônica, contudo sem os fundamentos das ideias interiorizados da Educação libertária, com o verdadeiro Ethos, cuja moral e ética são a personificação do Estado dentro do indivíduo pleno de liberdade.

Essa afirmação deve levar à reflexão sobre qual o papel da democracia, cujo sistema político é aclamado desde a Grécia antiga, para o exercício da liberdade. Dos primórdios, a democracia não pretendia tornar todos cidadãos iguais. Em Atenas, berço da democracia, copiada e mitificada, considerava como cidadãos apenas os homens alfabetizados com mais de vinte anos. Ser alfabetizado já implicaria em pertencer aos grupos sociais dominantes e não ser escravo ou estrangeiro. Mesmo que a Democracia Ateniense demonstrasse prosperidade e felicidade aos seus cidadãos, Sócrates a criticava por ter abandonado o princípio de Ethos nessa Educação. Isso Ihe custou a vida e lhe concebeu a imortalidade com sua ética. É sobre essa ética que se debruça Mello (1986) para dialogar sobre democracia, igualdade/liberdade. 


\section{LIBERDADE VS IGUALDADE = DEMOCRA- CIA?}

Sobre a luta pela instalação da democracia pode-se observar que ela está no contexto de liberdade e igualdade, ou somente pela igualdade, contra uma tirania, em que o discurso é sempre baseado na desigualdade entre os indivíduos desta sociedade, como foi na Revolução Russa (1917). Mas há outro desafio mais premente do que promover a igualdade entre esses indivíduos, como apregoam os mais enfáticos pela democracia igualitária: promover a liberdade dos indivíduos. Rousseau (2004), em sua obra Emílio, afirma que o homem é bom e deve ser educado para ser livre para suportar os males da vida ${ }^{6}$, exercendo suas escolhas de maneira autônoma na sua fase adulta.

Então, como poderá o indivíduo exercer sua liberdade respeitando o compromisso social e o cultural? O compromisso social faz do coletivo, entre o indivíduo e o Estado de maneira diferente do que o compromisso cultural, em que os valores do Estado estão inseridos no caráter pessoal, tratado aqui como Pessoa. O respeito aos Direitos do Homem, estendido como social, não pode estar acima dos Direitos da Pessoas, aqui com o compromisso cultural da pessoa. Sem considerar a dinâmica cultural das sociedades há pouca chance de coincidir os interesses pessoais com os do Estado pois,

Sem essa coincidência, proclamaram na IV Assembleia das Nações Unidas, não há maneiras de estabelecer um limite para a liberdade, exceto, naturalmente, coerção externa, isto é, imposição externa restritiva da liberdade (MELLO, 1986, p.91).

Assim, a revolução Russa ainda afirmara que, somente a partir da igualdade de classes seria possível se estabelecer a liberdade.

Temos assim diante de nós duas explicações diferentes que parecem se completar: primeiro, presentemente não existe liberdade nos países socialistas do tipo oriental, e a razão disso é que eles estão se esforçando em realizar

\footnotetext{
${ }^{6}$ Rousseau (2004), definiu como um dos pilares de sua proposta de educação a Educação Negativa, pelo qual, em linha gerais, recomenda que a criança seja preparada para não fazer o mau, ao invés de lhe apresentar somente as virtudes (conhecimento).
}

justiça e igualdade social e segundo, haverá liberdade nesses países somente quando houver igualdade completa (MELLO, 1986, p.91)

A promoção da liberdade nas sociedades democráticas ocidentais não se difere em seu intento, porém se demonstram cuidado que ela é exercida com maior vigor.

Para Mello (1986), um bom exemplo de promoção da liberdade plena é a proclamação dos Direitos do Homem, onde há, efetivamente, um desenvolvimento ético lapidado durante séculos da cultura ocidental. Essa liberdade prevista nesta proclamação prevê que a pessoa exerça sua autorregulação, exercendo sua liberdade como centro autônomo das decisões. Fica claro o desafio em justapor os interesses do Estado com o da pessoa, como já citamos acima. Contudo, há a limitação coercitiva que poderá agir procurando fortalecer a liberdade da sociedade em questão. É fato que essa construção demanda um retorno aos ideais gregos como em Platão, sobre o conceito do 'Estado dentro de nós'; ou então não prescindir de Lutero e sua concepção de autonomia individual da consciência religiosa; ou então da Lei Moral de Kant.

Agora, estabelecem-se os tipos de liberdade que apontam para suas origens: a liberdade externa, exercida pelo Estado com suas regras, dogmas e costumes; e a liberdade interna, no qual a própria pessoa carrega o discernimento de suas escolhas e refuta o individualismo, afinando-se aos interesses da sua sociedade. Embora pareçam antagônicas, Mello (1986, p.93) as considera uma etapa da outra, a externa da interna, cônscio de que,

No plano político a democracia é o contexto ideal para o desenvolvimento deste tipo de liberdade (a interna), mas a democracia em si mesma não é uma concepção que se tenha originado da ideia de liberdade. Sua verdadeira origem é a ideia de igualdade mais facilmente do que a ideia de liberdade (MELLO, 1986, p.93). [sic autor]

Isso define que a liberdade externa é oriunda de uma estrutura diferente da liberdade interna. São, portanto, democracias diferentes, uma cuja busca é pela igualdade e outra, pela liberdade. Afinal, as pessoas não são iguais, assim como não têm os mesmo objetivos e con- 
ceitos inatos. Diante de um sistema democrático é necessário que os indivíduos sejam considerados iguais diante das leis para que haja uma paz e prosperidade social. Contudo, é desejável que, a partir da Educação que advêm do Estado de cultura, algo maior que apenas um controle externo das ações e cerceamento de seus desejos e instintos pelo Estado, ou seja, por meio de uma coerção externa. É desejável que a Educação construa valores éticos, baseados no conceito do Ethos grego, formando o caráter, evocado por Sócrates no primeiro gole de cicuta. Numa frase célebre, Sócrates resume sua busca pela verdade: Conhece-te a ti mesmo. Fatalmente, voltados para as sombras, contempla-se apenas uma projeção do real, sem perceber que, no mito da caverna, há uma busca pela verdade, cuja ética se opõe à estética no discurso socrático-platônico, assim como estão a Estrutura de Poder e a Estrutura de Cultura revelados por Mello (1986).

Enquanto a liberdade externa é oriunda de uma Estrutura de Poder, em que promover a igualdade seja desistir da liberdade, sendo necessário o uso da coerção; por outro lado, há a Estrutura de Cultura, cuja liberdade interna é exercida em plenitude, pois as escolhas da pessoa são coincidentes com às do indivíduo. Mesmo tendo a possibilidade de fuga ou de retratação diante dos concidadãos atenienses pela vitória da democracia, Sócrates reafirmou que a ética como uma idiossincrasia da liberdade plena, interna e coerente.

Nesse embate entre ética ${ }^{7}$ e estética ${ }^{8}$, de poder e cultura, a liberdade é o foco da discussão: queremos ser livres? Antes, porém, seja necessário distinguir os conceitos de ética e estética sob a perspectiva Kierkegaard (apud Mello, 1986, p.270). Ele, cristão, refuta a razão como único instrumento para estabelecer a verdade $\mathrm{e}$ defendeu que o conhecimento se origina na fé a partir de três dimensões: a primeira a partir da estética, na busca do prazer imediato; o segundo a partir da ética, pelo qual se vale da liberdade (interna) na escolha do prazer imediato e do dever; e o terceiro na religiosidade, ou seja, pela fé. Elas são para Kierkegaard excludentes entre si cuja fruição da estética levaria à ética e, consequentemente à fé, a dimensão pensada por ele como a mais elevada. Neste sentido, o Ethos grego, cuja liberdade de escolha pelo refreio dos

${ }^{7}$ Valor interior de caráter transcendental.

${ }^{8}$ Valor exterior de caráter imanente. desejos e instintos em prol da sociedade interiorizada a partir da Educação à razão, é que encontram os autores Sócrates e Kierkegaard.

\section{DISCUSSÃO}

Retomando a pergunta anterior, certamente a resposta seria um retumbante não, devido aos acontecimentos políticos recentes. Contudo, há que se discutir, à luz das proposições do Ethos grego, qual o tipo de liberdade estamos aptos a exercer, ou melhor, qual o tipo de liberdade nos é permitido exercer. Então, assim a sociedade brasileira poderá decidir qual Educação servirá para ancorar o futuro modelo educacional brasileiro.

Pode-se prosseguir com a discussão entre ética e estética, e como esses preceitos podem definir o caminho mais adequado que a Educação Brasileira deve traçar. Antes, porém, a construção da ética passaria, sob a perspectiva de Kierkegaard (apud Mello, 1986, p.270), a partir da dicotomia de bem e de mal. Já em Platão este conceito de bem e de mal é transcendente, o que postularia à servidão da metafísica da existência de um deus imanente, de maneira a anular a possibilidade de saída da caverna, contentando-se apenas com a projeção da verdade pela luz do sol nas paredes da obscura caverna, personificado como o bem supremo, ou seja, Deus; enquanto a estética caminha sobre o campo da imanência, aqui refutado por Platão na busca da verdade. Essa verdade, sob a perspectiva de Platão, não é tratada como relativa ou ligada apenas ao mundo das ideias, outrossim, busca no mundo sensível, em que são imutáveis e por isso recomendáveis para a construção dos conhecimentos perfeitos.

Outra discussão paralela a postular diz respeito à intenção que a classe aristocrática tem diante do poder que exerce. Nietzsche (2007) define com certa ironia essa intenção quando destaca que:

Para os espíritos superiores, não é pequeno o perigo de que eles aprendam um dia ou outro a buscar novamente as alegrias terríveis que residem em destruir, em demolir pedra por pedra, situação na qual a ação criadora Ihes permaneceria absolutamente interdita, na ausência de instrumentos ou por qualquer outro capricho cruel do acaso (NIETZSCHE, 2007, p. 337). 
Para uma Educação solitária e individualista as possibilidades de liberdade são maiores, tendo em vista que a Educação intitulada 'de rebanho' não oferece possibilidade de liberdade, como oferece a primeira, como afirma Mendonça (2012):

\begin{abstract}
A educação aristocrática em Nietzsche trata da educação da grande e nobre individualidade e, em última instância, refere-se à educação do indivíduo solitário: uma educação para os espíritos livres e que estejam dispostos a empreender a autocrítica para exercer sua liberdade por meio da autossuperação. É por esta razão que a diferença é a base desta educação (MENDONÇA, 2012, p. 389).
\end{abstract}

Na perspectiva desse autor, a compreensão da diferença entre a Educação oferecida para aristocracia é fator preponderante para a conquista da liberdade. E acrescenta que a função da Educação não é a de proporcionar a igualdade entre os diferentes, mas oferecer a possibilidade de liberdade, apesar da diferença.

\section{CONSIDERAÇÕES FINAIS}

Por certo, temos na Educação a missão mais nobre que se possa atribuir que é a de perpetuar a humanidade, preservando sua identidade cultural e a sua liberdade. Ela deveria atuar, de acordo com Mello (1986), de maneira a 'provocar' o retorno do indivíduo à formação do Ethos, capacitando-o em sua liberdade interna, sem coerção externa, promovendo o desenvolvimento da cidadania diante da construção de uma democracia libertária, cuja verdade e essência fossem os pilares do conhecimento imutável e perfeito.

Fica evidente que nossa democracia brasileira atual é baseada na Estrutura de Poder, que buscando a igualdade, acentua o distanciamento da formação da liberdade, visando como foco o mercado de trabalho, como apresentado no exceto do $\mathrm{PCN}^{9}$. Como fruto dessa democracia temos a igualdade, amarga quando saboreado seu subproduto, a liberdade externa, "liberdade tão ambígua na sua natureza que pode coexistir com a escravidão" (MELLO, 1986, p.100). Tomando por referência o filósofo Aristóteles: igualdade não é sinônimo de liberdade,

${ }^{9}$ Parâmetros Curriculares Nacionais. pois a liberdade é um valor que está ligado à sua própria essência. É essencial reconhecer que a obra República de Platão é uma obra de educação, com a construção do Ethos, na concepção de um conceito aparentemente pleonástico de "liberdade independente" (MELLO,1986, p. 100).

Essa Educação causadora da liberdade interna, independente, ética "é o resultado de uma longa e concentrada reflexão sobre a obra platônica e suas relações com o contexto social e político dentro do qual surgiu (MELLO,1986, p.101). Formatar essa nova escola nos moldes da Estrutura de Cultura, pelo qual os indivíduos exercem sua liberdade interna com autonomia é um novo 'velho' paradoxo. Assim,

O objetivo final da Educação é a liberdade, mas ela se vê constantemente obrigada a suprimi-la para que dentro do ritmo dinâmico que lhe dá é próprio se realize o seu processo. Não há maneira de transmitir conhecimentos sem essa supressão. Quem pensa que a transmissão de conhecimentos é incompatível com a privação de liberdade não penetrou nem mesmo na antecâmara do laboratório pedagógico. O que a experiência educacional está constantemente mostrando é que a coerção é o método inevitável de toda a transmissão de conhecimentos. O homem se educa sobretudo através da imitação de modelos e a imitação é naturalmente, enquanto dura, inimiga da espontaneidade, forma insipiente de liberdade (MELLO, 1986, p.170).

A implantação de uma nova 'novíssima' educação, com seus currículos mirabolantes, enfoques mercadológicos e enfadonhas estratégias, é, certamente, um dos maiores desafios a serem contornados e adequados pelos gestores educacionais brasileiros. Dilema esse que norteia o educador mais atento, tentando preconizar o futuro, antes que a concorrência a faça.

Por fim, há que se pensar que a escola, espaço formal dedicado à construção da sociedade, deve objetivar ser democrática para que dela surja uma sociedade democrática. Deve ser um espaço adequado para o contraditório e o conflito, cujas diferenças serão fatalmente evidenciadas. No entanto, a liberdade interna exercitada fará diminuir as diferenças devido ao Ethos que na escola será cultivado, em respeito à natureza dos conflitos e das contradições en- 
contradas na sociedade atual.

\section{REFERÊNCIAS}

APEOESP - SITE. Disponível em: http://www. apeoesp.org.br/noticias/noticias/governoalckmin-acaba-com-aulas-de-geografia-historiae-ciencias/. Acesso em: 01 jun. 2013.

BRASIL. Secretaria de Educação Fundamental. Parâmetros curriculares nacionais: arte / Secretaria de Educação Fundamental. - Brasília: MEC /SEF, 1998. Disponível em: http://portal. mec.gov.br/seb/arquivos/pdf/arte.pdf. Acesso em: 22 maio 2013.

DURANT, W. A história da filosofia. Coleção Os Pensadores. São Paulo: Nova Cultural,1996.

KIERKEGAARD, S. Textos selecionados. Seleção e tradução por Ernani Reichmann. Curitiba: Editora Universidade Federal do Pará, 1986a.

MELLO, M. V. de. O conceito de uma educação da cultura - com referência ao esteticismo e à criação de um espírito ético no Brasil. Rio de Janeiro: Paz e terra, 1986.

NIETZSCHE, F. Genealogia da moral. Um escrito polêmico. Trad. Paulo César de Souza. São Paulo, Companhi das Letras, 2009.

NIETZSCHE, F. Escritos sobre Política. Trad. Noéli Correia de Melo Sobrinho. São Paulo, SP: Loyola, 2007, vol. I. 360p.

PLATÃO. A República. São Paulo: Martin Claret, 2000.

ROUSSEAU, J-J. Emílio, ou, Da educação. 3. ed. São Paulo: Martins Fontes, 2004.

ROUSSEAU, J-J. Do Contrato Social. 2. ed. Trad. Lourdes Santos Machado. São Paulo: Abril Cultural , 1973. (Coleção Os Pensadores).

ROUSSEAU, J-J. Discurso Sobre a Origem e os Fundamentos da Desigualdade entre os Homens. 2. ed. Trad. Lourdes Santos Machado. São Paulo: Abril Cultural , 1978. (Coleção Os Pensadores).

VITORINO,A.J.R. Da Crise do Moderno Conceito de História para a "Educação Patrimonial Ético-
Humanista”. XXVI Simpósio Nacional de História - ANPUH. Anais... São Paulo,2011. Disponível em: http://www.snh2011.anpuh.org/resources/ anais/14/1300713435 ARQUIVO_Anpuh_2011_ Texto_Ensino_de_Historia_e_Educacao_ Patrimonial.pdf. Acesso em: 07 jun. 2013.

\section{EL ETHOS DE LA CULTURA EN LA EDUCACIÓN BRASILEÑA}

Resumen: Esta investigación discute el papel de la Educación a partir de la afirmación explicitada en los PCN de 1998 mediante la visión de Mario Vieira de Mello (1912 - 2006). En búsqueda de calidad en la enseñanza, los currículos son adecuados a las realidades urbanas a partir de modelos importados, muchas veces sin un análisis profundo del papel que la sociedad desea que la Educación desempeñe. La reflexión sobre los conceptos de libertad e igualdad para la democracia pueden llevar los educadores a otros posicionamientos, considerando autores que buscan en la Educación la trascendencia del Ethos, no de la manera posible, sino enfrentando las idiosincrasias y paradojos que presenta nuestra democracia. Delante de esa proposición, el artículo responde a la siguiente pregunta:- ¿La Educación Brasileña puede dar soporte necesario para una democracia con plena libertad a sus ciudadanos? Como respuesta, se sugiere la implantación de una nueva Educación cuyo gran reto es hacerla suficiente para atender la demanda por profesionales capacitados y debidamente educados para ejercer su plena libertad en la democracia, cultivando la libertad interna a partir del concepto de Ethos.

Palabras clave: Educación; Ética; Calidad en la Educación. 